\title{
Single-Center Experience With the Dual-Focus Storz Modulith SLX-F2 Lithotripter: A Retrospective Study
}

\author{
Jason Chandrapal ${ }^{\mathrm{a}}$, Andrew Tang ${ }^{\mathrm{a}}$, Andrew Navetta ${ }^{\mathrm{a}}$, Brandon Trojan ${ }^{\mathrm{a}}$, Allan Haynes ${ }^{\mathrm{a}}$, \\ Werner de Riese ${ }^{a}$, Stephanie Filleur ${ }^{\mathrm{a}, \mathrm{b}}$, Thomas Nelius ${ }^{\mathrm{a}, \mathrm{c}}$
}

\begin{abstract}
Background: To calculate the modified efficiency quotient of the mobile Storz Modulith SLX-F2 lithotripter, to identify factors determining clinical succes rate and to identify complications and limitations with this device. Comparison of the results with reported data from other institutions for the same machine and other types in the peer review literature will be made.

Methods: The study design is a retrospective chart review. Inclusion criteria include male and female and patients who were treated in the Texas Tech University Health Sciences Center for urinary calculi with the Storz Modulith SLX-F2 lithotripter between September 2006 and June 2011. During this period, 447 patients with single stones were treated, and 10 patients with radiolucent stones and 21 patients with incomplete follow-up were excluded. The patients were followed up with plain radiography and/or renal ultrasound to assess the clinical succes rate. Univariate and multivariate analyses were performed to identify the factors determining the clinical success rate.
\end{abstract}

Results: Follow-up was complete for 416 patients. Mean age was $46.1 \pm 14.4$ years. The mean numbers of shock waves given were 2,457 and 2,838 for renal and ureteral stones, respectively. Mean stone sizes were $9.3 \pm 4.5 \mathrm{~mm}$ and $9.7 \pm 4.9 \mathrm{~mm}$ for renal and ureteral stones, respectively. Mean body mass index was $30.5 \pm$ $7.04 \mathrm{~kg} / \mathrm{m}^{2}$. The overall clinical success rate after one ESWL treatment was $84.6 \%$ (85.4\% and $83.6 \%$ for renal and ureteral stones, respectively). The modified efficiency quotient was 0.69 . On univariate analysis, clinical success rate was associated with smaller stone size $(<10 \mathrm{~mm}, \mathrm{P}=0.016)$, and absence of a ureteral stent

Manuscript accepted for publication October 10, 2013

${ }^{a}$ Department of Urology, Texas Tech University Health Sciences Center Lubbock, Lubbock, TX, USA

${ }^{b}$ Department of Immunology and Molecular Microbiology, Texas Tech University Health Sciences Center Lubbock, Lubbock, TX, USA

${ }^{\mathrm{c} C}$ orresponding author: Thomas Nelius, Department of Urology, Texas Tech University Health Sciences Center Lubbock, Lubbock, TX, USA. Email: thomas.nelius@ttuhsc.edu

doi: http://dx.doi.org/10.14740/wjnu111w
(31.7\% vs. $10.5 \% ; \mathrm{P}=0.0002)$. Presence of lower calyx stones $(\mathrm{P}=$ $0.04)$ was a negative predictor of clinical success. On multivariate analysis, lower calyx stones, smaller stone size and the absence of a ureteral stent continued to be significant determinants of clinical success status. All complications were minor with a complication rate of $4.3 \%$.

Conclusions: The mobile Storz Modulith SLX-F2 lithotripter is clinically effective in the management of solitary renal and ureteral stones. It has an adequate modified efficiency quotient combined with a favorable safety profile. Major advantages are the increased treatment depth in combination with exceptionally high weight limit and a dual-focus system.

Keywords: Extracorporal shockwave lithotripsy; Dual-focus system; Stones; Treatment; Urolithiasis; SLX-F2

\section{Introduction}

Extracorporal shock wave lithotripsy (ESWL) represents one of the first-line treatment options for upper urinary tract stones [1]. ESWL has changed the treatment of kidney stones dramatically over the past 30 years. The first successful ESWL was performed with the Dornier HM1 lithotripter in 1980 [2]. New developments led rapidly to the introduction of the unmodified and modified Dornier HM3 lithotripter generations. Some of the modified Dornier HM3 lithotripters are still in use as a recent randomized study by the group of Studer demonstrated [3]. The HM3 (Dornier, Wessling, Germany) is still considered the reference or gold standard by which all other lithotripters are judged [2]. The HM3 lithotripter generations have major drawbacks including the necessity for large space, limited ability to perform auxiliary techniques and limited use of fluoroscopy [4]. These limitations and drawbacks resulted in the development of newer lithotripter generations with variation in machine size, portability, shock wave source, treatment head coupling method, treatment power and imaging for stone targeting (ultrasound and fluoroscopy) [4]. Although these modifications have certain advantages, they also differ in their stone fragmentation rate and complication profile [5]. World-wide multiple 
Table 1. Technical Parameters of the Storz Modulith SLX-F2

\begin{tabular}{|c|c|}
\hline Parameter & Description \\
\hline Shock wave source & Electromagnetic cylindrical coil source \\
\hline Coupling system & Water filled cushion \\
\hline Focusing system & Parabolic reflection system \\
\hline Maximal treatment depth (mm) & $\leq 180$ \\
\hline \multicolumn{2}{|c|}{ Variable focus volume at level 50 (mm) } \\
\hline Wide & $36 \times 4.8 \times 4.7$ \\
\hline Narrow & $20 \times 2 \times 2$ \\
\hline Variable focus pressure (MPa) & $6.4-107 \pm 20 \%$ \\
\hline \multicolumn{2}{|c|}{ Peak compressional acoustic pressure (MPa) } \\
\hline Wide & $16-44$ \\
\hline Narrow & $18-107$ \\
\hline \multicolumn{2}{|l|}{ Energy per shot $(\mathrm{mJ})$} \\
\hline Wide & $2.9-15$ \\
\hline Narrow & $2.5-16$ \\
\hline Imaging system & $\begin{array}{l}\text { In-line imaging system with up to } 30^{\circ} \text { lateral } \\
\text { fluoroscopy }\end{array}$ \\
\hline
\end{tabular}

lithotripter generations are simultaneously in use; however, only limited data comparing different lithotripter machines in randomized trials are available compared to the number of ESWLs performed annually. It can be estimated that more than one million patients are treated annually with ESWL in the US alone. In Medicare patients with a diagnosis of urolithiasis, rates of ESWL treatment remained relatively stable over 1992, 1995 and 1998, with a rate of 10,943 to 11,738 per 100,000 Medicare beneficiaries for ESWL [6]. However, evidence exists that kidney stone disease is increasing, and as a result, surgical treatments, including ESWL will also increase [7-11]. This will have tremendous financial implication on health care systems world-wide. Because of its minimally invasive approach it has many advantages over other available treatment options. The use of externally applied, focused, high-intensity acoustic energy causes only minimal collateral damage; however, this comes with an overall lower stone-free rate compared to other more invasive treatment methods, such as ureteroscopy in combination with laser lithotripsy or percutaneous nephrolithopaxy [12]. Despite its minimally invasive characters ESWL is not without risks and can cause minor and major short- and long-term complications such as capillary damage, renal parenchymal or subcapsular hematoma, renal failure and hypertension [13, 14]. The overall complication rate ranges in the literature between $5 \%$ and $20 \%$ [15]. Limitations of ESWL include low fragmentation rate for some renal stones requiring multiple treatment sessions [16-18]. Additionally, certain anatomical conditions (calyceal diverticulum or unfavorable infundibulopelvic angles) and also stone location (lower versus middle and upper pole calyx) impact significantly stone-free rates after ESWL treatment [19]. For the reasons stated above each ESWL machine should be evaluated for its treatment efficacy. According to personnel communication with Karl Storz Lithotripsy-America, Inc. 117 Storz Modulith SLX-F2 lithotripters are in use in the US. Given this high number and the minimal number of published data regarding the efficacy of these machines further clinical reports are urgently needed. Randomized clinical trials are difficult to obtain with this type of treatment and therefore well performed high volume non-randomized studies are of great importance in order to compare different ESWL machines. Here we report our results with the dual-focus system Modulith SLX-F2 ${ }^{\mathrm{TM}}$ (Karl Storz Lithotripsy-America, Inc.) in a single institution. The aim of the present study was to calculate the efficiency quotient (EQ) of the latest fourth-generation mobile Storz 
Table 2. Patient Characteristics $(n=416)$

\begin{tabular}{ll} 
Characteristics & Value/SD/Range* \\
\hline Mean age in years & $46.1 \pm 14.4($ range: $6-83)$ \\
Male/female patients & $243(58.4 \%) / 173(41.6 \%)$ \\
Mean body mass index $\left(\mathrm{kg} / \mathrm{m}^{2}\right)$ & $30.5 \pm 7.04($ range: $16.5-58.8)$ \\
Race & \\
$\quad$ Caucasian & Male: $147(35.3 \%)$ female: $95(22.8 \%)$ \\
$\quad$ Hispanic & Male: $65(15.5 \%)$ female: $66(15.9 \%)$ \\
African-American & Male: $8(1.90 \%) ;$ female: $3(0.70 \%)$ \\
Other & Male: $23(5.50 \%)$ female: $9(2.20 \%)$
\end{tabular}

*were applicable; SD: standard deviation.

Modulith SLX-F2 lithotripter and to assess the efficacy and safety of this ESWL machine for managing solitary urinary calculi.

\section{Patients and Methods}

The study received Institutional Review Board approval (L11-143) at Texas Tech University Health Sciences Center (TTUHSC) Lubbock, TX. The study design is a retrospective analysis. Inclusion criteria include male and female and patients who were treated at TTUHSC for urinary calculi with the Storz Modulith SLX-F2 lithotripter between September 2006 and February 2011. During this period 447 patients with single stones were treated, and 10 patients with radiolucent stones and 21 patients with incomplete followup were excluded. Follow-up data were completed for 416 patients with radiopaque stones. Necessary follow-up exams included plain radiography (KUB) and renal ultrasound to assess the clinical success. Exclusion criteria from the study were: ureteropelvic junction stenosis, urinary tract obstruction of other causes than stone disease, multiple stones, stone diameter $>2 \mathrm{~cm}$, stones in a lower calyx with unfavorable anatomy as described previously [20]. Stones larger than $20 \mathrm{~mm}$ were treated with other surgical options. Preoperative assessment comprised urine culture, KUB, renal ultrasound and computer tomography (CT). Selected patients had a ureteric stent (JJ stent) placed according to the surgeon's preference, depending on stone burden, presence of intractable pain or sepsis, and/or solitary kidneys. ESWL was performed with the mobile Modulith SLX-F2 in combination with the mobile C-arm fluoroscopic unit (OEC 9800 Plus; GE Healthcare, Salt Lake City, UT) with manual positioning to obtain two different views. Treatment was performed on an outpatient basis and all patients were treated under general anesthesia. All enrolled patients were treated by the same technician under the supervision of an urologist. Treatment variables, for example power settings and number of shocks delivered, were at the discretion of the operator. Briefly, the patients were placed supine (except for distal ureteric stones, for which patients were prone or supine). Stones had to be radiographically located in two planes in order to be eligible for treatment. Specifications of the Modulith SLX-F2 lithotripter are summarized in Table 1. The Modulith SLX-F2 lithotripter has two focal zones available: the standard narrow focus was used at the beginning of the treatment to achieve rapid stone disintegration, and the wider focus was used after initial disintegration was demonstrated. Maximal energy levels for renal and ureteral stones were 7 and 9, respectively. A maximum of 3,000 shock waves were used for each ESWL session; however, the exact number of shock waves was at the discretion of the treating urologist. Patients were followed up KUB, renal ultrasound or CT to assess the stone-free status. Clinical success was defined as absence of radiopaque residual fragments, including also the presence of fragments $\leq 4 \mathrm{~mm}$. Re-treatment was defined as repeat ESWL performed for the same stone (re-treatment group). Patients undergoing further surgical options other than ESWL were classified as treatment failures. Patients requiring auxiliary post-ESWL procedures (JJ stent) were included in the stone-free group, unless they needed curative auxiliary procedures (ureteroscopy or percutaneous approaches), which was considered treatment failure. To consider also other pre- and post-ESWL curative auxiliary measures, such as ureteroscopy and percutaneous nephrolitholapaxy, a modified EQ was calculated as described previously by Rassweiler et al: EQ modified = percentage of stone-free patients + percentage of curative auxiliary measures $/ 100 \%$ + percentage of repeat ESWL + percentage of pre-ESWL auxiliary measures + percentage of post-ESWL 
Table 3. Descriptive Statistic of Stone Localization

\begin{tabular}{|c|c|}
\hline Characteristics & N/SD \\
\hline \multicolumn{2}{|l|}{ Laterality } \\
\hline Left & $225(54.1 \%)$ \\
\hline Right & $191(45.9 \%)$ \\
\hline \multicolumn{2}{|l|}{ Renal localization } \\
\hline Renal pelvis & $116(27.9 \%)$ \\
\hline Upper calyx & $36(8.7 \%)$ \\
\hline Middle calyx & $45(10.8 \%)$ \\
\hline Lower calyx & $97(23.3 \%)$ \\
\hline \multicolumn{2}{|l|}{ Ureteral localization } \\
\hline Proximal ureter & $88(21.2 \%)$ \\
\hline Middle ureter & $16(3.8 \%)$ \\
\hline Distal ureter & $18(4.3 \%)$ \\
\hline Mean stone size (mm) & $9.3 \pm 4.5($ range: $5-20)$ \\
\hline \multicolumn{2}{|l|}{ Stone size $(\mathrm{mm})$} \\
\hline$\geq 5 ;<10$ & $256(61.5 \%)$ \\
\hline$\geq 10 ; \leq 20$ & $160(38.5 \%)$ \\
\hline
\end{tabular}

adjuvant measures [21].

\section{Statistical analysis}

Statistical analysis was performed using the commercially available statistical program from XLSTAT (Addinsoft SARL, New York, NY, USA) and statistical package for Social Sciences for Windows, version 19 (SPSS, Chicago, IL). The Student's t-test was used to compare continuous variables, such as age, body mass index (BMI), stone size, number of shock waves and energy level. Fisher's exact test and Chi-square test were used for categorical variables, with two-tailed $\mathrm{P} \leq 0.05$ considered statistically significant. Univariate and multivariate analyses using logistic regression were performed to identify factors determining clinical success rates.

\section{Results}

Follow-up was complete for 416 patients (243 males and 173 females, ratio: 1:1.4) treated at TTUHSC with the Mo- dulith SLX-F2 lithotripter from September 2006 to June 2011 (Table 2). The mean age of the study population was $46.1 \pm 14.4$ years. The included patients had either symptomatic solitary renal (294) or ureteric stones (122). All included patients had radiopaque urinary calculi. The mean stone size was $9.3( \pm 4.5)$ for all sites, with $9.7( \pm 4.9)$ for renal and $8.6( \pm 3.2)$ for ureteral stones. Renal stones were significantly larger than the ureteral stones $(\mathrm{P}=0.04(0.012$; 2.03)). Stratified by stone location, 225 (54.1\%) were leftsided and $191(45.9 \%)$ were right-sided. Table 3 contains a detailed description of the renal and ureteral localization. Race distribution is summarized in Table 2, with the majority of patients being Caucasians (242 patients, 58.2\%). For all included patients ESWL was done in an outpatient setting, including all auxiliary procedures. The mean numbers of shock waves delivered for renal and ureteral stones were 2,457 and 2,838, respectively, which were statistically not significant $(\mathrm{P}=0.091(-593.1 ; 168.4))$. A significant difference was observed for the delivered energy levels $(\mathrm{P}<0.05$ $(-1.41 ;-1.07))$. The mean energy levels delivered to renal and ureteral stones were 6.96 and 8.21 , respectively.

The overall 3-month clinical success rate after a sin- 
Table 4. Treatment Outcomes Depending on Auxiliary Procedures

\begin{tabular}{|c|c|c|c|}
\hline Characteristics & Clinical success & Failure & $P$ value \\
\hline \multicolumn{4}{|c|}{ Auxiliary procedures } \\
\hline \multicolumn{4}{|l|}{$\mathrm{JJ}$ stent } \\
\hline Yes & 37 & 20 & 0.0002 \\
\hline No & 316 & 43 & \\
\hline \multicolumn{4}{|c|}{ Nephrostomy } \\
\hline Yes & 6 & 0 & 0.5971 \\
\hline No & 347 & 63 & \\
\hline
\end{tabular}

gle ESWL treatment was $84.6 \%$ (renal $85.4 \%$ and ureteral $83.6 \% ; \mathrm{P}=0.654)$. Patients with renal stones of $\leq 4 \mathrm{~mm}$ were followed expectantly; those with stone $>4 \mathrm{~mm}$ (number) underwent repeated ESWL treatment or other auxiliary treatment option with curative intent, resulting in an overall re-treatment rate of $11.29 \%$. The re-treatment rates were $11.9 \%$ for renal and $9.8 \%$ for ureteral stones, $\mathrm{P}=0.613$ ). Fifty-seven (13.7\%) patients had pre-ESWL JJ stents, and stenting was at the discretion of the treating urologist. Placement of a JJ stent impacted clinical success rate significantly. Patients in the failure group had in $31.7 \%$ a $\mathrm{JJ}$ stent placed compared to $10.5 \%$ in the clinical success group $(\mathrm{P}=0.0002)$ (Table 4 and Fig. 1). Nephrostomy placement did not impact clinical success rate $(P=0.597)$. Forty-seven $(11.29 \%)$ patients underwent repeated ESWL and auxiliary procedures including ureteroscopy and LASER lithotripsy and were therefore considered treatment failures. On the basis of these data, a modified EQ of 0.69 was calculated for our series. On univariate analysis stone size and stone location significantly affected the success rate (Table 5). The mean stone sizes in the clinical success group and failure group were $9.1 \mathrm{~mm}( \pm$ $4.01)$ and $10.5 \mathrm{~mm}( \pm 6.78)$, respectively $(\mathrm{P}=0.003(-2.66$; $-0.08)$ ). Therefore, stones $\geq 5 \mathrm{~mm}$ and $<10 \mathrm{~mm}$ resulted in significantly greater stone-free rates compared to stones $\geq$ 10 and $\leq 20 \mathrm{~mm}$ (88.3 vs. $79.4 \%$, respectively; $\mathrm{P}=0.016$ ). Stone size $<10 \mathrm{~mm}$ was an independent factor predicting

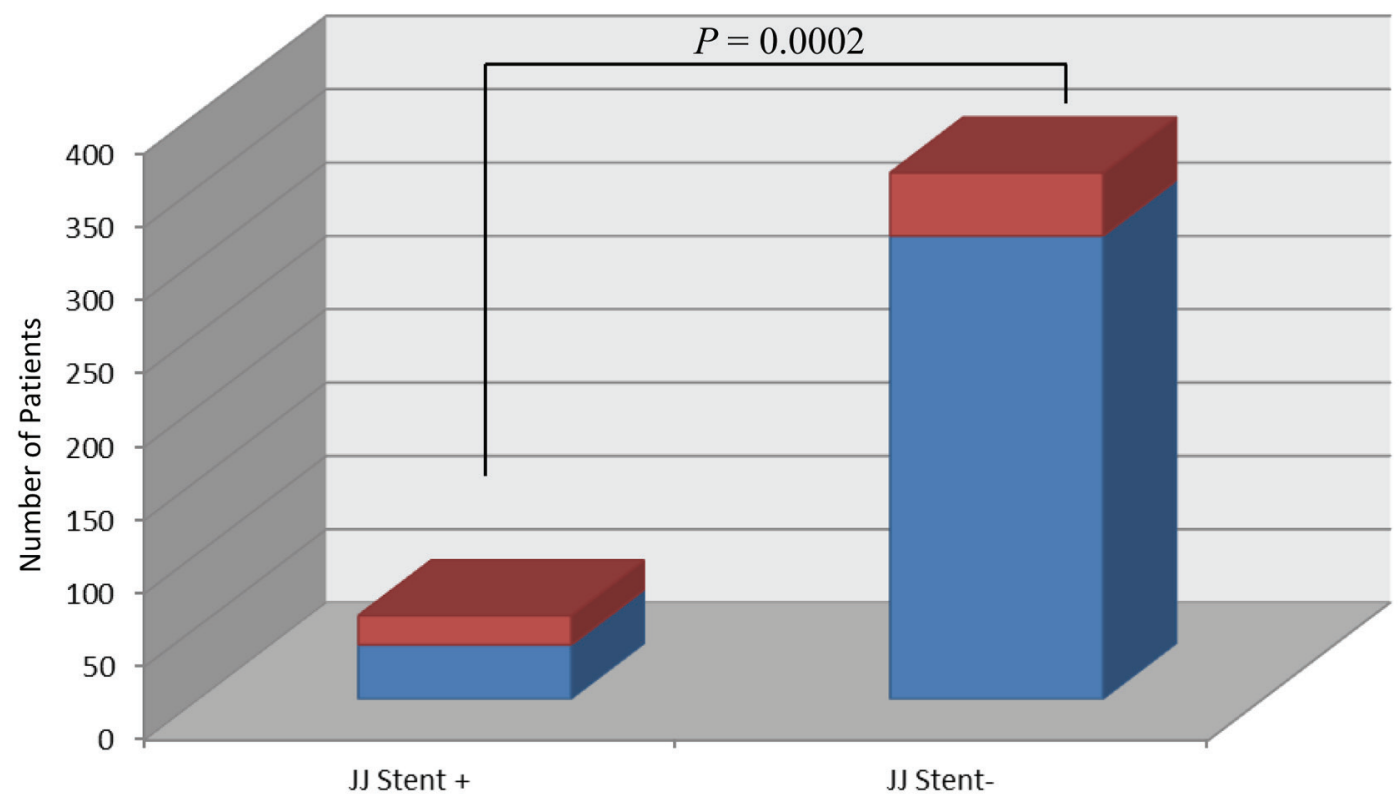

Success $\square$ Failure

Figure 1. JJ stent presence and failure rate. 
Table 5. Specific Patient and Stone Characteristics in Relationship to Clinical Success Status Versus Treatment Failure

\begin{tabular}{|c|c|c|c|c|}
\hline Variable & Stone-free & Failure & P value & $95 \% \mathrm{CI}$ \\
\hline Age (years) & 45.6 & 49.1 & 0.086 & $(-7.47 ; 0.49)$ \\
\hline Male & 201 & 42 & 0.166 & \\
\hline Female & 152 & 21 & & \\
\hline Mean body mass index $\left(\mathrm{kg} / \mathrm{m}^{2}\right)$ & 30.5 & 30.4 & 0.486 & $(-1.80 ; 2.52)$ \\
\hline \multicolumn{5}{|l|}{ Race } \\
\hline Caucasian & 208 & 34 & 0.666 & - \\
\hline Hispanic & 110 & 21 & & \\
\hline African-American & 8 & 3 & & \\
\hline Other & 27 & 5 & & \\
\hline \multicolumn{5}{|l|}{ Stone characteristics } \\
\hline Mean stone size (mm) & 9.1 & 10.5 & 0.003 & $(-2.66 ;-0.08)$ \\
\hline \multicolumn{5}{|l|}{ Stone size (mm) } \\
\hline$\geq 5 ;<10$ & 226 & 30 & 0.016 & - \\
\hline$\geq 10 ; \leq 20$ & 127 & 33 & & \\
\hline \multicolumn{5}{|l|}{ Laterality } \\
\hline Left & 192 & 33 & 0.671 & - \\
\hline Right & 161 & 30 & & \\
\hline \multicolumn{5}{|l|}{ Renal localization } \\
\hline Renal pelvis & 102 & 14 & $0.04 * 0$ & - \\
\hline Upper calyx & 34 & 2 & & \\
\hline Middle calyx & 42 & 3 & & \\
\hline Lower calyx & 73 & 24 & & \\
\hline \multicolumn{5}{|l|}{ Ureteral localization } \\
\hline Proximal ureter & 70 & 18 & 0.092 & - \\
\hline Middle ureter & 14 & 2 & & \\
\hline Distal ureter & 18 & 0 & & \\
\hline
\end{tabular}

${ }^{*}$ renal or ₹ureteral stone location only; ${ }^{\circ}$ for detailed analysis (see Fig. 2); Cl: confidence interval.

clinical success after single ESWL treatment. The clinical success rate for lower calyx stones was significantly lower compared to all other renal stone locations (Table 5 and Fig. 2). No significant differences were observed for ureteral stones. Age and side of stone location did not correlate with clinical success rate in our series. Additional evaluated parameters are summarized in Table 5. On multivariate analysis, lower calyx stones, smaller stone size and the absence of a JJ stent continued to be significant determinants of clinical success status.

Documented complications were only minor and manageable on an outpatient basis. Complications included urinary tract infections ( 9 patients), fever $>38^{\circ} \mathrm{C}$ ( 2 patients) and gross hematuria for $>24$ ( 3 patients). Cardiac arrhythmias were documented in 12 patients, requiring only gating of the shock waves without further intervention. Subcapsular renal hematomas were encountered in four patients. One patient with subcapsular renal hematomas was admitted to the 


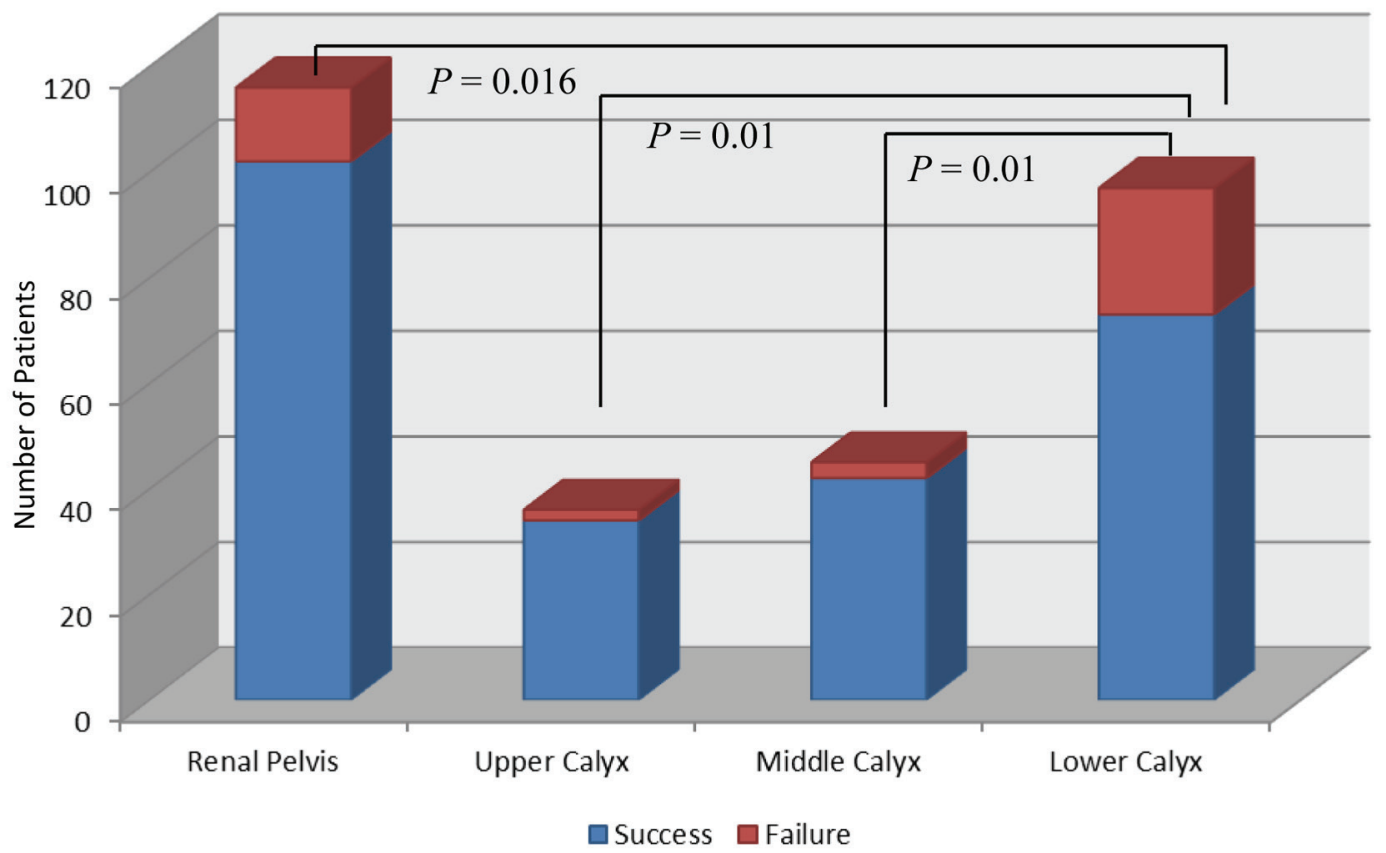

Figure 2. Renal stone localization and clinical success rate.

hospital for observation. The overall complication rate in our series was $4.3 \%$ (without the observed cardiac arrhythmias).

\section{Discussion}

Despite significant advances in the development of lithotripter machines, the Dornier HM3 is still the reference standard against which all other newer generation ESWL machines are measured [22]. Major drawbacks of this machine are its size and handling. An ongoing trend is the development toward smaller, more portable, less expensive machines, without the requirement of extensive installation. This could be achieved with different shock wave sources, advancements in focusing elements, development of smaller coupling devices and improved imaging techniques [23]. However, these modifications came on the expense of less energy delivery and therefore lower success rates, and higher re-treatment rates [24].

A recent development is the mobile Modulith SLX-F2 lithotripter with several unique features including dual-focus system, increased focus depths and significantly increased patient weight limit. These modifications should allow optimal adaptation of shock wave delivery by higher pressures and good energy concentration (standard focus) to disintegrate ureteral stones and lower pressures with wider focal zone to treat larger stones within the renal pelvis. The increased focal depth of $180 \mathrm{~mm}$ in combination with the increased patient weight limit of $225 \mathrm{~kg}(495 \mathrm{lb})$ allows to treat additionally morbidly obese patients. The total number of mobile Modulith SLX-F2 lithotripter in use in the US is 117. Only four peer-reviewed studies (including one conference abstract [25]) evaluating this specific lithotripter machine were published so far (Table 6) [3, 4, 25-27]. This is a clear discrepancy between the extent of use and available reported data regarding efficacy and complication rate. One of the studies was a randomized study comparing the Modulith SLX-F2 with the HM3 lithotripter [3]. However, comparison of study results is difficult due to the fact that ESWL in European studies is not performed under general anesthesia, whereas general anesthesia is frequently used in the US. The results of the present study demonstrate that the mobile Modulith SLX-F2 lithotripter is an effective device in fragmenting solitary renal and ureteral stones (Table 6). The overall clinical success rate was $84.6 \%$ with an EQ of 0.69 . These data are comparable to previous published results with the Modulith SLX-F2 (Table 6) [3, 4, 25-27]. Furthermore, the results of our study implicate that the latest fourth-generation mobile Modulith SLX-F2 lithotripter has comparable efficiency to the original electrohydraulic HM3 lithotripter. However, it is important to note that in the present study, clinical success was defined as the complete absence of fragments or stones $\leq 4 \mathrm{~mm}$ on KUB and/or ultrasound. In the present study, lower calyx stones, smaller stone size and the absence of a JJ stent were significant determinants of clinical success status on multivariate analysis. Other published series using the Modulith SLX-F2 lithotripter describe the number of shocks, stone location, stone size and age as sig- 
Table 6. Comparison of the Modulith SLX-F2 With Other Portable and Non-Portable Lithotripters

\begin{tabular}{|c|c|c|c|c|c|c|c|}
\hline Ref & Lithotripter machine & $\begin{array}{l}\text { SW } \\
\text { source }\end{array}$ & $\begin{array}{l}\# \\
\text { patients }\end{array}$ & $\begin{array}{l}\text { Mean stone } \\
\text { size }(\mathbf{m m})\end{array}$ & $\begin{array}{l}\text { Stone-free } \\
\text { rate }(\%)\end{array}$ & $\begin{array}{l}\text { Re-treatment } \\
\text { rate }(\%)\end{array}$ & EQ \\
\hline $\begin{array}{l}\text { de Sio et al } \\
{[4]}\end{array}$ & $\begin{array}{l}\text { Modulith SLX-F2 } \\
\text { (focus NA) }\end{array}$ & EM & 233 & 12.6 & 76.3 & 11.5 & 0.64 \\
\hline $\begin{array}{l}\text { Albala et al } \\
{[25]}\end{array}$ & $\begin{array}{l}\text { Modulith SLX-F2 } \\
\text { (focus NA) }\end{array}$ & EM & 599 & 7 & 69.8 & N/A & N/A \\
\hline $\begin{array}{l}\text { Suzuki et al } \\
\text { [27] }\end{array}$ & $\begin{array}{l}\text { Modulith SLX-F219 } \\
\text { (standard vs. wide } \\
\text { focus) }\end{array}$ & EM & 361 & $\begin{array}{l}\text { Renal: } 14 ; \\
\text { Ureteral: } 11\end{array}$ & N/A & N/A & $\begin{array}{l}0.553 \\
\text { vs. } \\
0.565\end{array}$ \\
\hline $\begin{array}{l}\text { Elkoushi et } \\
\text { al [26] }\end{array}$ & $\begin{array}{l}\text { Modulith SLX-F2 } \\
\text { (standard focus) }\end{array}$ & EM & 474 & $\begin{array}{l}\text { Renal: } 10.5 \text {; } \\
\text { Ureteral: } 8.7\end{array}$ & 77 & 14.7 & 0.66 \\
\hline $\begin{array}{l}\text { Zehnder et } \\
\text { al [3] }\end{array}$ & Modulith SLX-F2" & EM & 415 & N/A & $\begin{array}{l}67 \text { (solitary } \\
\text { stones) }\end{array}$ & 11 & 0.58 \\
\hline Present study & $\begin{array}{l}\text { Modulith SLX-F2 } \\
\text { (standard and wide } \\
\text { focus) }\end{array}$ & EM & 416 & 9.3 & $84.6^{*}$ & 11.29 & 0.69 \\
\hline $\begin{array}{l}\text { Cass et al } \\
{[31]}\end{array}$ & Dornier HM3 & EH & 2,402 & $<20^{* *}$ & 70 & 6 & 0.64 \\
\hline $\begin{array}{l}\text { Sheir et al } \\
\text { [32] }\end{array}$ & Dornier Lithotripter S & EM & 347 & 12.7 & 88.5 & 34.6 & 0.54 \\
\hline $\begin{array}{l}\text { Nabi et al } \\
{[33]}\end{array}$ & $\begin{array}{l}\text { Dornier Compact } \\
\text { Delta }\end{array}$ & EM & 137 & 10 & 82 & 29.3 & 0.53 \\
\hline $\begin{array}{l}\text { Portis et al } \\
{[34]}\end{array}$ & $\begin{array}{l}\text { Healthtronics } \\
\text { LithoTron }\end{array}$ & EH & 38 & 9.6 & 13.4 & 21 & N/A \\
\hline $\begin{array}{l}\text { Jain et al } \\
{[35]}\end{array}$ & $\begin{array}{l}\text { Healthtronics } \\
\text { LithoTron }\end{array}$ & $\mathrm{EH}$ & 256 & 8 & 66 & 7.7 & 0.59 \\
\hline $\mathrm{Ng}$ et al [36] & Wolf Piezolith 3000 & $\mathrm{PE}$ & 26 & N/A & 36 & N/A & N/A \\
\hline $\begin{array}{l}\text { Albala et al } \\
\text { [37] }\end{array}$ & Medstone STS-T & EH & 326 & 8.2 & 52.8 & N/A & 0.43 \\
\hline $\begin{array}{l}\text { Vega et al } \\
{[38]}\end{array}$ & Siemens Modularis & EM & 1,000 & 12.2 & $>90$ & 19 & N/A \\
\hline $\begin{array}{l}\text { White et al } \\
\text { [39] }\end{array}$ & $\begin{array}{l}\text { Doriner Compact } \\
\text { Delta }\end{array}$ & EM & 4,621 & N/A & 58.5 & 7.2 & 0.51 \\
\hline $\begin{array}{l}\text { Heretis et al } \\
{[40]}\end{array}$ & Dornier Lithotriper S & EM & 140 & $7.6-9.5$ & 75 & 7 & 0.67 \\
\hline $\begin{array}{l}\text { Pemberton et } \\
\text { al [41] }\end{array}$ & $\begin{array}{l}\text { Technomed Sonolith } \\
\text { Vision }\end{array}$ & $\mathrm{EC}$ & 107 & 8.9 & 88.8 & 20.6 & 0.67 \\
\hline $\begin{array}{l}\text { Nomikos et } \\
\text { al [42] }\end{array}$ & Sonolith Vision & EM & 309 & 10.8 & 75 & 16.8 & 0.62 \\
\hline $\begin{array}{l}\text { Egilmez et al } \\
\text { [43] }\end{array}$ & Siemens Modularis & EM & 2,670 & N/A & 79 & N/A & 0.67 \\
\hline
\end{tabular}

N/A: data not available; SW: shock wave; EM: electromagnetic; PE: piezoelectric; EC: electroconductive. ${ }^{*}$ Clinical success rate; ${ }^{* *}$ for most of the patients. 
nificant predictors of a stone-free outcome on multivariate analysis $[25,26]$. Stones size was frequently found to be a significant determinant of stone-free rate. The present study did not find an association between patient age and clinical success rate as described by Elkoushy et al [26]. This could be attributed to the fact that the overall mean age of the present study was significant lower compared to other studies $[26,27]$. Therefore, additional studies are needed to evaluate the effect of age on clinical success. The laterality of stone location did not impact clinical success rate in our study, whereas Elkoushy et al reported that right-sided stones resulted in significantly greater stone-free rates compared with left-sided stones [26]. On the other hand, Elkoushy et al did not find an association between intrarenal or ureteral stone location and stone-free status and attributed this finding to the low samples size of his study [26]. The presence of a JJ stent and its impact on stone-fee rate or clinical success rate is discussed controversially in the literature. Some authors could demonstrate an impact of ureteral stenting [26], whereas others did not see an impact or did not describe it $[3,4]$. This discrepancy could be explained by the fact that in most studies stent placement is at the discretion of the treating urologist (stone sizes might be different at which a stent is placed). Based on our results and experience, one should hold off with stent placement if clinically possible as it might interfere with stone passage. Therefore, additional studies are needed to evaluate further the effect of age, presence of a $\mathrm{JJ}$ stent, body side and stone composition on clinical success. The impact of BMI on clinical success or stone-free rate was never described for the Modulith ${ }^{\circledR}$ SLX-F2 lithotripter. The present study of the mobile Modulith SLX-F2 lithotripter reports additionally for the first time the impact of BMI on the clinical success rate. The lithotripter has an extended 180 $\mathrm{mm}$ focus depth and an exceptionally high weight limit of $225 \mathrm{~kg}$, making it especially useful for obese patients. In our study, no significant difference between BMI in the clinical success group and failure group was seen. BMI seems to be less likely an adverse factor with the development of medical devices with increased limits and shock wave sources with higher penetration depths.

Suziki et al found that the EQ for ureteral stones was greater with the standard narrow focus (0.798 vs. 0.626). Their study failed to demonstrate a significant difference for renal stones [27]. Comparing reported data in this regard is difficult because of significant differences of mean stones sizes of the studies [28]. The present study used the standard narrow focus at the beginning of the treatment and the wider focus after fragmentation of the stones. However, the significance of this approach remains to be determined. In terms of collateral damage to the kidneys, an in vitro model with perfused porcine kidneys did not demonstrate differences between the standard and wide focus [29]. Therefore, additional randomized clinical trials are urgently needed in order to examine the significance of the standard narrow fo- cus and the wider focus, as well as their sequencing in the treatment of renal and ureteral stones. Documented intraoperative and post-operative complications were only minor and easily manageable. In our series subcapsular hematomas were often asymptomatic and detected on routine ultrasound examinations. The incidence after ESWL treatment is probably higher than reported in the literature as most patients are routinely followed up with KUB rather than CT or ultrasound, especially in the US. Hematomas could become a clinical issue if patients are re-treated with ESWL in a short interval.

Limitations of the present study include its retrospective, non-randomized character. It is also problematic to compare results for this lithotripter machine with other studies due to differences in patient selection, definition of stonefree status or clinical success status. Indications for auxiliary procedures vary also from institution to institution. Similar to other reports, the study also failed to examine fragmentation and stone-free rates/clinical success rates based on stone composition [4]. This is due to the fact that most patients do not pass fragments large enough for stone analysis. We are aware of the problems to use the clinical success rate. This might lead to better outcome results; however, the re-treatment rate was not significantly different from other reported studies, implicating that clinical success is a useful parameter in determining the efficiency of lithotripters. A significant number of smaller stone fragments are not well visualized on KUB and ultrasound and can be therefore missed. Conversely, CT has a much higher sensitivity in detecting small residual fragments; however, its use in routine followup after ESWL treatment is clinically not practical. This is attributed to greater radiation exposure and cost compared to KUB and/or ultrasound exams [30]. Because of this fact, most reported studies do not use routine CT in their followup. This discrepancy makes it in our opinion obsolete to use the term "stone-free" rather than clinical success rate. In our opinion, the stone-free rate is less useful as outcome parameter than the re-treatment rate.

\section{Conclusion}

The mobile Storz Modulith SLX-F2 lithotripter is clinically effective in the management of solitary renal and ureteral stones. Its adequate EQ combined with its flexibility (mobile and fully integrated) and a favorable safety profile justifies its use in clinical practice. Further major advantages are the increased treatment depth in combination with exceptionally high weight limit and a dual-focus system. The mobile Modulith SLX-F2 lithotripter is a reliable machine in terms of clinical success and EQ despite frequent transportation. Using clinical success rate corresponds better to the need of treating urologists. The stone-free group of most clinical studies is contaminated with patients with small residual fragments which are overlooked on KUB and ultrasound and 
which are often clinically insignificant. Therefore the term stone free is misleading.

\section{Conflict of Interest}

None declared.

\section{References}

1. Tiselius HG, Ackermann D, Alken P, Buck C, Conort P, Gallucci M. Guidelines on urolithiasis. Eur Urol. 2001;40(4):362-371

2. Chaussy C, Brendel W, Schmiedt E. Extracorporeally induced destruction of kidney stones by shock waves. Lancet. 1980;2(8207):1265-1268.

3. Zehnder P, Roth B, Birkhauser F, Schneider S, Schmutz R, Thalmann GN, Studer UE. A prospective randomised trial comparing the modified HM3 with the MODULITH(R) SLX-F2 lithotripter. Eur Urol. 2011;59(4):637-644.

4. De Sio M, Autorino R, Quarto G, Mordente S, Giugliano F, Di Giacomo F, Neri F, et al. A new transportable shock-wave lithotripsy machine for managing urinary stones: a single-centre experience with a dual-focus lithotripter. BJU Int. 2007;100(5):1137-1141.

5. Teichman JM, Portis AJ, Cecconi PP, Bub WL, Endicott RC, Denes B, Pearle MS, et al. In vitro comparison of shock wave lithotripsy machines. J Urol. 2000;164(4):1259-1264.

6. Margaret SP, Elizabeth AC, Curhan GC. Urolithiasis. In: Litwin MS, Saigal CS, eds. Urologic Diseases in America. Washington, DC: US Government Printing Office, 2007. NIH Publication No. 07-5512 US Department of Health and Human Services, Public Health Service, National Institutes of Health, National Institute of Diabetes and Digestive and Kidney Diseases. 2007:283-319.

7. Amato M, Lusini ML, Nelli F. Epidemiology of nephrolithiasis today. Urol Int. 2004;72 (Suppl 1):1-5.

8. Pearle MS, Calhoun EA, Curhan GC. Urologic diseases in America project: urolithiasis. J Urol. 2005;173(3):848857.

9. Romero V, Akpinar H, Assimos DG. Kidney stones: a global picture of prevalence, incidence, and associated risk factors. Rev Urol. 2010;12(2-3):e86-96.

10. Stamatelou KK, Francis ME, Jones CA, Nyberg LM, Curhan GC. Time trends in reported prevalence of kidney stones in the United States: 1976-1994. Kidney Int. 2003;63(5):1817-1823.

11. Trinchieri A, Coppi F, Montanari E, Del Nero A, Zanetti $\mathrm{G}$, Pisani E. Increase in the prevalence of symptomatic upper urinary tract stones during the last ten years. Eur Urol. 2000;37(1):23-25.
12. Pearle MS, Lingeman JE, Leveillee R, Kuo R, Preminger GM, Nadler RB, Macaluso J, et al. Prospective, randomized trial comparing shock wave lithotripsy and ureteroscopy for lower pole caliceal calculi $1 \mathrm{~cm}$ or less. J Urol. 2005;173(6):2005-2009.

13. Kaude JV, Williams CM, Millner MR, Scott KN, Finlayson B. Renal morphology and function immediately after extracorporeal shock-wave lithotripsy. AJR Am J Roentgenol. 1985;145(2):305-313.

14. McAteer JA, Evan AP. The acute and long-term adverse effects of shock wave lithotripsy. Semin Nephrol. 2008;28(2):200-213.

15. D’Addessi A, Vittori M, Racioppi M, Pinto F, Sacco E, Bassi P. Complications of extracorporeal shock wave lithotripsy for urinary stones: to know and to manage thema review. ScientificWorldJournal. 2012;2012:619820.

16. Dretler SP. Stone fragility--a new therapeutic distinction. J Urol. 1988;139(5):1124-1127.

17. Kim SC, Burns EK, Lingeman JE, Paterson RF, McAteer JA, Williams JC, Jr. Cystine calculi: correlation of CT-visible structure, CT number, and stone morphology with fragmentation by shock wave lithotripsy. Urol Res. 2007;35(6):319-324.

18. Klee LW, Brito CG, Lingeman JE. The clinical implications of brushite calculi. J Urol. 1991;145(4):715-718.

19. Lingeman J MB, Evan AP. Surgical management of upper urinary tract calculi. In: Wein AJ, Kavoussi LR, Novick AC, et al. eds. Campbell-Walsh Urology. Philadelphia: Sauders, 2007:1431-1507.

20. Elbahnasy AM, Shalhav AL, Hoenig DM, Elashry OM, Smith DS, McDougall EM, Clayman RV. Lower caliceal stone clearance after shock wave lithotripsy or ureteroscopy: the impact of lower pole radiographic anatomy. J Urol. 1998;159(3):676-682.

21. Rassweiler J, Henkel TO, Kohrrmann KU, Potempa D, Juenemann KP, Alken P. Lithotriptor technology: present and future. J Endourol. 1992;6:1-13.

22. Drach GW, Dretler S, Fair W, Finlayson B, Gillenwater J, Griffith D, Lingeman J, et al. Report of the United States cooperative study of extracorporeal shock wave lithotripsy. J Urol. 1986;135(6):1127-1133.

23. Rassweiler J, Tailly G, Chaussy C. Progress in lithotriptor technology. EAU Update Series. 2005;17-36.

24. Kohrmann KU, Rassweiler JJ, Manning M, Mohr G, Henkel TO, Junemann KP, Alken P. The clinical introduction of a third generation lithotriptor: Modulith SL 20. J Urol. 1995;153(5):1379-1383.

25. Albala DM, Turk TM, Fulmer BR, Koleski F, Andriole G, Davis BE, Eure GR, et al. Periurethral transurethral microwave thermotherapy for the treatment of benign prostatic hyperplasia: an interim 1-year safety and efficacy analysis using the thermatrx TMx-2000. Tech Urol. 2000;6(4):288-293.

26. Elkoushy MA, Hassan JA, Morehouse DD, Anidjar 
M, Andonian S. Factors determining stone-free rate in shock wave lithotripsy using standard focus of Storz Modulith SLX-F2 lithotripter. Urology. 2011;78(4):759763.

27. Suzuki K, Yamashita Y, Yoshida M, Matuzaki J. [A single center experience with a lithotripsy machine "Modulith SLX-F2": evaluation of dual focus system and clinical results]. Hinyokika Kiyo. 2010;56(2):81-86.

28. Tiselius HG. How efficient is extracorporeal shockwave lithotripsy with modern lithotripters for removal of ure- teral stones? J Endourol. 2008;22(2):249-255.

29. Heacker A, Leistner R, Knoll T, et al. Ex vivo evaluation of renal injury of a new electromagnetic shockwave generator with user selectable dual focus size. BJU Int. 2004;94:8.

30. Osman Y, El-Tabey N, Refai H, Elnahas A, Shoma A, Eraky I, Kenawy M, et al. Detection of residual stones after percutaneous nephrolithotomy: role of nonenhanced spiral computerized tomography. J Urol. 2008;179(1):198200; discussion 200 . 